\title{
Prevalence and Characterization of the Cerebral Palsy in Maceió, a Northeast City of Brazil
}

\author{
Márcia Andreya Zanon ${ }^{1,2}$, Amanda Kelly Martin Araújo, Edson V. C. Neto ${ }^{1}$, Larissa C. Mendes ${ }^{1}$, \\ David Balbino Pascoal ${ }^{3}$, Euclides Maurício Trindade Filho ${ }^{1,2,3^{*}}$, Reidson Beiriz Verçosa ${ }^{4}$, \\ Lysien Ivania Zambrano5, Janise Dal Pai6, José Cláudio da Silva ${ }^{2,3,7}$ \\ ${ }^{1}$ Faculdade Estácio de Sá de Alagoas, Maceió, Brasil \\ ${ }^{2}$ Universidade Estadual de Ciências da Saúde de Alagoas-UNCISAL, Maceió, Brasil \\ ${ }^{3}$ Centro Universitário CESMAC, Maceió, Brasil \\ ${ }^{4}$ Centro Universitário UNIT, Maceió, Brasil \\ ${ }^{5}$ Facultad de Ciencias Medicas, Universidad Nacional Autónoma de Honduras, Tegucigalpa, Honduras \\ ${ }^{6}$ Universidade Federal de São Paulo-UNIFESP, São Paulo, Brasil \\ ${ }^{7}$ Faculdade UNIRB de Arapiraca, Arapiraca, Brasil \\ Email: ^emtfilho@gmail.com
}

How to cite this paper: Zanon, M.A., Araújo, A.K.M., Neto, E.V.C., Mendes, L.C., Pascoal, D.B., Filho, E.M.T., Verçosa, R.B., Zambrano, L.I., Dal Pai, J. and da Silva, J.C. (2018) Prevalence and Characterization of the Cerebral Palsy in Maceió, a Northeast City of Brazil. World Journal of Neuroscience, 8, 333-341. https://doi.org/10.4236/wins.2018.83026

Received: June 1, 2018

Accepted: July 17, 2018

Published: July 20, 2018

Copyright (C) 2018 by authors and Scientific Research Publishing Inc. This work is licensed under the Creative Commons Attribution International License (CC BY 4.0).

http://creativecommons.org/licenses/by/4.0/ (c) (i) Open Access

\begin{abstract}
Background: Cerebral palsy is a group of disorders arising from a static damage or brain development defects occurring during fetal life and in the first months of life. Methods: The sample consisted of 800 individuals living in 50 districts of the city of Maceio. A standardized questionnaire was applied. Results: The prevalence of cerebral palsy in the sample was 5/1000. All were born at term, $75 \%$ were male, $50 \%$ had severe cerebral palsy and $50 \%$ was moderate. $75 \%$ had quadriplegia and $25 \%$ had diplegia. Fifty percent of the cerebral palsy was caused by meningitis and $50 \%$ for prolonged labor. Conclusions: The prevalence of cerebral palsy in Maceió is $140.38 \%$ higher than the highest prevalence found in developed countries, predominantly in low-income and related to postnatal infection in families.
\end{abstract}

\section{Keywords}

Cerebral Palsy, Epidemiology, Motor Disorders, Muscle Weakness, Muscle Tonus

\section{Introduction}

Cerebral Palsy $(\mathrm{CP})$ is a group of brain diseases of a non-progressive and per- 
manent character, which results from some lesion or developmental anomalies occurring during the fetal life or in the first months of life. The CP motor disorders are often accompanied by feeling, perception, cognition, communication and behavior disorders. There may also be epilepsy, and usually secondary musculoskeletal problems affecting the development of movement and posture, leading to high health care costs and reduced life expectancy [1] [2].

Other shortcomings such as low physical and lower aerobic capacity are due to long-term effects of abnormal forces and stretches imposed on the musculoskeletal system resulting from primary brain injury [3] [4]. Studies have shown that the weakness and muscles contracture is due not only to inadequate recruitment of motor units but to changes in mechanical stresses and hormonal factors that lead to complex histological and variable changes in the skeletal striated muscle. There are changes in the type of muscle fibers, making them shorter, which compromise daily living activity [4] [5] [6] [7].

Several etiologies may be linked to CP. It has been observed that in addition to prematurity, other well-known factors, including defects of brain development, hypoxia, perinatal stroke, shock, as well as fetal and/or neonatal inflammation may be etiologic factors [8] [9] [10]. It is the most common cause of motor incapacitation in childhood, with an incidence of 2 to 3 per 1000 live births, occurring 20 to 30 times more often in premature or low birth weight children. Due to complexity, etiology, pathology, clinical manifestations and progression, the literature agrees to consider the $\mathrm{CP}$ as a set of disorders, rather than a uniform and isolated entity; thus contributing to an efficient development of treatment or research guidelines [9] [10] [11] [12] [13].

The study of new and old cases is very useful because it allows greater knowledge about the disorder. This work determines the prevalence of CP and provides information about the pathology in the city of Maceió.

\section{Material and Methods}

A cross-sectional study was carried out, comprising 800 individuals and distributed in 880 residences. This number was stipulated based on Maceió population (year 2004), referring to the 2000 Census of the Brazilian Institute of Geography and Statistics (Instituto Brasileiro de Geografia e Estatística-IBGE) [14]. The research began after approval by the Research Ethics Committee of Estácio de Alagoas (no 6152413), and in accordance with the Directives and Norms Regulating Research Involving Human Beings (Resolution 466/12 of the National Health Council, Ministry of Health of Brazil). The residences are located in the 50 districts (Municipal Law 4952/2000), in Maceió city state of Alagoas (Brazil). Initially, was chosen the main street of each neighborhood, and randomly by means of lottery a house. From this house, the 10th house was chosen in sequence, folding right and left alternately.

The owner of the residence was invited to participate in the research if had in residency, any case of Cerebral Palsy. After accepting, the owner signed a free 
and informed consent. A standardized questionnaire was then applied, consisting of 20 personal, socioeconomic, cultural and specific items about the disease, which included: name and age of the mother, age and sex of the child, family income, parental educational level, gestation time, type of delivery, intercurrences during pregnancy, topographic distribution, type of tonus, motor functions, speech and orthoses use. The evaluation was done by analyzing the answers given to the items of the questionnaire, based on the knowledge of the clinical history of the disease and physical examination at the time of the visit, in which inspection, palpation, passive movement and then trophic observation were performed. The tonus was assessed through passive movement and palpation. While the severity, through the presence of voluntary movements, orthopedic problems, respiratory and cognitive function. All analyzes of Cerebral Palsy were made by consensus among the authors of the study.

\section{Results}

Four patients were diagnosed with Cerebral Palsy in a population sample of 800 individuals. These individuals correspond to $0.1 \%$ of the Maceio population. Therefore, the prevalence rate its 5/1000. Normal childbirth was predominant which occurred in public hospitals and with half of them being cesarean. All cases received medical and hospital care during pregnancy, prenatal care, labor delivery and postpartum. The variables surveyed about the general characteristics of childbirth are described in Table 1.

The maternal age at the time of the birth ranged from 23 to 36 years, while family income ranged from 500.00 to 9000.00 Reais (R\$). It was verified that among the four patients with Cerebral Palsy, three lived in the periphery, whose parents have educational level varying from illiteracy to full secondary education, and one in the central city area, whose parents have a complete university level as may be seen in table below (Table 2).

Two cases were considered severe which have accompanied by severely limited motor capacity, even with the aid of devices, while the other two

Table 1. Characteristics of the delivery labor of people with cerebral palsy in the city of Maceió ( $\mathrm{n}=4)$.

\begin{tabular}{cc}
\hline Variables & $\mathrm{N}(\%)$ \\
\hline Notcesarean & $50 \%$ \\
Cesarian & $50 \%$ \\
Public hospital & $75 \%$ \\
Private Hospital & $25 \%$ \\
At term & $100 \%$ \\
Pre-term & $0 \%$ \\
Post-term & $0 \%$
\end{tabular}

Values are expressed as percentages. 
Table 2. General characteristics of pregnancies of patients with cerebral palsy in the city of Maceió $(\mathrm{n}=4)$.

\begin{tabular}{cc}
\hline Variables & $\mathrm{N}(\%)$ \\
\hline From the outskirts of the city & $75 \%$ \\
From the central region & $25 \%$ \\
Until high school & $75 \%$ \\
Higher level & $25 \%$ \\
Health care & $100 \%$ \\
\hline
\end{tabular}

Values are expressed as percentages.

situations were classified as moderate, due to the difficulty of locomotion outside the home, significant motor limitation, and need for transportation. Hypertonia present in most cases was flexor and spastic, while diplegia was less common. All patients with $\mathrm{CP}(\mathrm{n}=4)$ used the wheelchair, did not experience orthostatism, did not roam and had no independence for activities of daily living (ADLs) (Table 3).

Only one patient, who had control of trunk and cervical tonus, presented some degree of sedestation. He had a reasonable control of voluntary movements, as well as gross motricity. Physiotherapeutic treatment was neglected by a modest part of the family members, what was responsible for a finding of only $25 \%$ of regularly physiotherapeutic treatment (Table 3 ).

However, something that attracted a great deal of attention and was considered a great surprise in our results was the difficulty in the diagnosis of patients with CP. In one case, it occurred at the 6 years of age. A second patient was diagnosed only at the end of adolescence, that is, at 18 years, while the other two occurred in adulthood at the 26 and 35 years.

\section{Discussion}

In this study four patients with Cerebral Palsy were found out of a total of 800 individuals, which results in a prevalence of 5/1000 (full-term newborns). Considering the scarcity of prevalence studies, mainly in Brazil, the comparative analysis between the data recorded by this research and those already published in the Brazilian literature is limited. It was necessary to compare the prevalence found in this study with the information on the prevalence of Cerebral Palsy in developed countries-therefore, in an international context.

In a review conducted at 1950, Paneth \& Kiely found the prevalence of 2/1000 live births as a reasonable estimate for industrialized countries [14]. The prevalence of Cerebral Palsy in the Nordic countries declined after 1970, due to improvements of the care for preterm and infants of low birth weight. There were a decrease in perinatal mortality with a subsequent increase in morbidity among survivors, occurring increase in the prevalence of paralysis what was observed both in a Swedish study and Finnish [15]. 
Table 3. General characteristics of patients with cerebral palsy in the city of Maceió $(\mathrm{n}=$ 4).

\begin{tabular}{|c|c|}
\hline Variables & $\mathrm{N}(\%)$ \\
\hline Etiology by meningitis & $50 \%$ \\
\hline Etiology due to intercurrent delivery & $50 \%$ \\
\hline Moderate severity & $50 \%$ \\
\hline Intense gravity & $50 \%$ \\
\hline Tetraplegia & $75 \%$ \\
\hline Diplegia & $25 \%$ \\
\hline Swallowing bearers & $100 \%$ \\
\hline Uses orthosis & $100 \%$ \\
\hline Male & $75 \%$ \\
\hline Women & $25 \%$ \\
\hline Carriers who speak & $0 \%$ \\
\hline AVDs & $0 \%$ \\
\hline Cervical posture control & $25 \%$ \\
\hline Sedestation & $25 \%$ \\
\hline Treats with physiotherapy regularly & $25 \%$ \\
\hline Treats with physiotherapy sporadically & $25 \%$ \\
\hline Does not treats with physical therapy & $50 \%$ \\
\hline
\end{tabular}

Values are expressed as percentages.

In England, Pharoah et al. (1987; 1989; 1990) showed a decrease in perinatal mortality in low birth weight infants from 25 to 10/1000 from 1966 to 1977. During this period, the prevalence of Cerebral Palsy was 1.5/1000 live births, occurring an increase considerable just in the low birth weight infants. According to a study conducted in Australia, perinatal mortality decreased from 27 to $12 / 1000$ births, while the prevalence of Cerebral Palsy did not vary over the period between 1968 and 1981. But the increase in low-weight survivors resulted in an increase in cases of Paralysis Cerebral [15]-[20]. A multicenter European study executed in 14 centers of 8 countries with information on 6000 children with Cerebral Palsy in the period from 1980 to 1990 showed prevalence of 2.08/1000 live births [20] [21].

Cerebral Palsy cases predominated in men (75\% of cases) compared to women [20] [21]. In a survey conducted in 2002 covering 3 areas of the USA (northern Alabama, Atlanta and Wisconsin) with 8-year-old children, it was found that in all regions the prevalence of Cerebral Palsy was higher in boys than in girls, in a ratio of 1.4:1 [20]. A study conducted in western Ireland in 2002 took into account the prevalence analysis for the period 1990 to 1999, with 85 children at least 5 years of age, showed that $68 \%$ of children with Cerebral Palsy, were boys [21]. 
It was observed that boys are more predisposing than girls to present adverse consequences of Cerebral Palsy, in addition to higher risk factors commonly occurring in boys. Immeasurable biological variables contribute to disadvantages related to neurodevelopment in boys [13].

The benefits of normal delivery labor are numerous, both for the mother and for her baby, ranging from a better recovery to the reduction of the risks of hospital infection. According to data from the Live Birth Information System referent to 2002, the national rate of cesarean deliveries is $39 \%$, higher than those recommended by the World Health Organization (WHO), which recommends that this figure should not exceed $15 \%$. According to a study carried out in Rio de Janeiro and published in 2004, in public hospitals there is a higher incidence of normal deliveries than cesareans [14].

In this study, the number of normal deliveries exceeded that of cesareans, being in a ratio of $3: 1$. It was found that three deliveries were normal, with two occurred in public hospitals. So, this result is in agreement with literature which reports that normal deliveries is higher than cesarean deliveries in public hospitals. The World Health Organization (WHO) highlights some operational indicators, among which about 200 cases of bacterial meningitis per year are expected for each group of 100.000 children under five years of age [15]. Of the patients with Cerebral Palsy, three male and one female, two had Cerebral Palsy due to meningitis and two had prolonged labor. Those who were affected by meningitis, one female and other male, presented Cerebral Palsy due to the infectious process directly related to the sequela of paralysis. The other two presented Cerebral Palsy due prolonged delivery labor, which, as a consequence, caused hypoxic-ischemic injury, a typical fact in these cases.

The educational level is not directly related to Cerebral Palsy, but the higher level of schooling probably causes the families to become aware of the care for a successful pregnancy, avoiding diseases and consequent sequels.

Depending on the location and extent of impairment, the Cerebral Palsy manifests as monoplegia, hemiplegia, diplegia, triplegia or tetraplegia [18]. Tetraplegia or quadriplegia occurs in $9 \%$ to $43 \%$ of patients. In a study with 100 cases of Cerebral Palsy, the spastic form occurred 55 times, with a predominance of tetraparesis in 25 cases [18]. In Cerebral Palsy, the spastic or pyramidal form is the most frequent in $88 \%$ of the cases [20] [21]. The diplegic form occurs in $17.7 \%$, is much less severe than the tetraplegias and the neurological condition is characterized by motor impairment of the lower limbs, while the upper limbs being poorly affected [22]. According to the literature, the results of this research show that the spastic form of Cerebral Palsy is the most common, making a total of $75 \%$, and of the 4 patients found, 3 presented the spastic form and with tetraplegia, whereas 1 of him, i.e. $25 \%$, presented the diplegic form.

Children with Cerebral Palsy have as main characteristic the motor impairment, which influences their functional performance. According to Schwartzman (1993) and Souza \& Ferraretto (1998), Cerebral Palsy can be classified according 
to two criteria: the type of motor dysfunction present, which includes extrapyramidal or dyskinetic (athetoid, choreic and dystonic), ataxic, mixed and spastic; or due to the topography of the damages, that is, region of the affected body.

In addition to the motor disorder, which is mandatory for the characterization of Cerebral Palsy, the clinical picture may also include other accessory manifestations with variable frequency: mental deficiency, epilepsy, language disorders, visual disturbances, behavior disorders and orthopedic disorders [21]. The prognosis of patients with Cerebral Palsy usually depends on the type of paralysis and its severity. More than $90 \%$ of children with Cerebral Palsy survive to adulthood. Only the most severely affected (unable to perform any personal care) have a much shorter life expectancy. In this research, an adult life expectancy for Cerebral Palsy patients was verified, thus corroborating evidence from the literature cited above [22] [23] [24].

Within this context, we analyzed the motor functions present in patients with Cerebral Palsy who were part of this prevalence study. All patients found in the study, had the swallowing function preserved and only one presented control of the trunk and neck with reasonable control of voluntary movements, as well as gross motricity. According to a survey conducted by the Department of Obstetrics and Gynecology, University College Hospital (Galway, Ireland) [25], 18\% of 85 children at least 5 years of age did not roam. In this research, it was seen that all patients with Cerebral Palsy did not walk and did not experience orthostatism. Therefore, gait-related deficit is common to both researches.

\section{Conclusion}

Prevalence of CP in Maceió is higher than those found in developed countries, occurring predominantly in low-income families, and the main causes are postnatal meningitis infection and prolonged labor. This study contributes to the expansion of knowledge and understanding of the problem of $\mathrm{CP}$ prevalence in the Brazilian public health context. It also helps to indicate that better and more targeted attention should be given during prenatal care, labor and lactation. Preventive work and improved care of premature and low birth weight infants are fundamental. It should be made by a multi-professional health team and public-private health managers. Similarly, more research and multicentric studies are necessary to provide information about the $\mathrm{CP}$ on general and specific populations.

\section{Declaration of Interest}

The authors state no conflict of interest and have received no payment in preparation of this manuscript.

\section{References}

[1] Carol, L. (2013) Richards and Francine Malouin. Cerebral Palsy: Definition, Assessment and Rehabilitation. Handbook of Clinical Neurology, 111, 184-195. 
[2] Strauss, D., Shavelle, R., Reynolds, R., Rosenbloom, L. and Day, S. (2007) Survival in Cerebral Palsy in the Last 20 Years: Signs of Improvement? Developmental Medicine \& Child Neurology, 49, 86-92. https://doi.org/10.1111/j.1469-8749.2007.00086.x

[3] Rose, J., Gamble, J.G., Medeiros, J., Burgos, A. and Haskell, W.L. (1989) Energy Cost of Walking in Normal Children and in Those with Cerebral Palsy: Comparison of Heart Rate and Oxygen Uptake. Journal of Pediatric Orthopedics, 9, 276-279. https://doi.org/10.1097/01241398-198905000-00004

[4] Gage, J.R. and Schwartz, M.H. (2009) Consequesnces of Brain Injury on Musculoskeletal Development. In: Gage, J.R., Schwartz, M.H., Koop, S.E., et al., Eds., The Identification and Treatment of Gait Problems in Cerebral Palsy, 2nd Edition, Clinics in Developmental Medicine Nos 180-181, MacKeith Press, London, 107-129.

[5] Henderson, R.C., Lark, R.K., Gurka, M.J., Worley, G., Fung, E.B., Conaway, M., Stallings, V.A. and Stevenson, R.D. (2002) Bone Density and Metabolism in Children and Adolescents with Moderate to Severe Cerebral Palsy. Pediatrics, 110, e5. https://doi.org/10.1542/peds.110.1.e5

[6] Samson-Fang, L., Fung, E., Stallings, V.A., Conaway, M., Worley, G., Rosenbaum, P., Calvert, R., O'donnell, M., Henderson, R.C., Chumlea, W.C., Liptak, G.S. and Stevenson, R.D. (2002) Relationship of Nutritional Status to Health and Societal Participation in Children with Cerebral Palsy. Journal of Pediatrics, 141, 637-643. https://doi.org/10.1067/mpd.2002.129888

[7] Damiano, D.L. (2006) Activity, Activity, Activity: Rethinking our Physical Therapy Approach to Cerebral Palsy. Physical Therapy, 86, 1534-1540. https://doi.org/10.2522/ptj.20050397

[8] Oskoui, M., Coutinho, F., Dykeman, J., Jette, N. and Pringsheim, T. (2013) An Update on the Prevalence of Cerebral Palsy: A Systematic Review and Meta-Analysis. Developmental Medicine \& Child Neurology, 55, 509-519. https://doi.org/10.1111/dmcn.12080

[9] Rosenbaum, B. and Varvin, S. (2007) The Influence of Extreme Traumatization on Body, Mind and Social Relations. International Journal of Psychoanalysis, 88, 1527-1542. https://doi.org/10.1111/j.1745-8315.2007.tb00758.x

[10] Novak, I., McIntyre, S., Morgan, C., et al. (2013) A Systematic Review of Interventions for Children with Cerebral Palsy: State of the Evidence. Developmental Medicine \& Child Neurology, 55, 885-910. https://doi.org/10.1111/dmcn.12246

[11] McIntyre, S., Badawi, N., Blair, E. and Nelson, K.B. (2015) Does Aetiology of Neonatal Encephalopathy and Hypoxic-Ischaemic Encephalopathy Influence the Outcome of Treatment? Developmental Medicine \& Child Neurology, 57, 2-7. https://doi.org/10.1111/dmcn.12725

[12] Lopez-Pison, J., Garcia-Jimenez, M.C., Monge-Galindo, L., et al. (2014) Our Experience with the Aetiological Diagnosis of Global Developmental Delay and Intellectual Disability: 2006-2010. Neurologia, 29, 402-407.

[13] Lungu, C., Hirtz, D., Damiano, D., Gross, P. and Mink, J.W. (2016) Report of a Workshop on Research Gaps in the Treatment of Cerebral Palsy. Neurology, 87, 1293-1298. https://doi.org/10.1212/WNL.0000000000003116

[14] Universidade Federal de Pelotas. (2009) Acessado em 30 out. http://www.epidemio-ufpel.org.br/proesf/pdf

[15] Paneth, N. and Kiely, J.L. (1984) The Frequency of Cerebral Palsy: A Review of Population Studies in Industrialized Nation since 1950. In: Stanley, F. and Alberman, E., Eds., The Epidemiology of the Cerebral Palsies, Blackwell Scientific Publi- 
cations, Oxford, England, 46.

[16] Hagberg, B., Hagberg, G., Olow, I. and von Wendt, L. (1989) The Changing Panorama of Cerebral Palsy in Sweden. V. The Birth Year Period 1979-82. Acta Paediatrica Scandinavica, 78, 283-290. https://doi.org/10.1111/j.1651-2227.1989.tb11071.x

[17] Pharoah, P.O., Cooke, T.E., Rosenbloom, L. and Cooke, R.W. (1987) Trends in Birth Prevalence of Cerebral Palsy. Archives of Disease in Childhood, 62, 379-384. https://doi.org/10.1136/adc.62.4.379

[18] Pharoah, P.O.D., Cooke, T. and Rosenbloom, L. (1989) Acquired Cerebral Palsy. Archives of Disease in Childhood, 64, 1013-1016. https://doi.org/10.1136/adc.64.7.1013

[19] Pharoah, P.O.D., Cooke, T., Cooke, R.W. and Rosenbloom, L. (1990) Birthweight Specific Trends in Cerebral Palsy. Archives of Disease in Childhood, 65, 602-606. https://doi.org/10.1136/adc.65.6.602

[20] Stanley, F. (1984) Perinatal Risk Factor in Cerebral Palsy. In: Stanley, F. and Alberman, E., Eds., The Epidemiology of the Cerebral Palsies in Clinics in Developmental Medicine, Blackwell Scientific Publishers, Inc., Philadelphia, No. 87, 98.

[21] Surveillance of Cerebral Palsy in Europe (SCPE) (2002) Prevalence and Characteristics of Children with Cerebral Palsy in Europe. Developmental Medicine \& Child Neurology, 44, 633-640.

[22] Yeagin, A.M., Von Naarden, B.K., Doemberg, N.S., Benedict, R.E., Kirby, R.S. and Durkin, M.S. (2008) Prevalence of Cerebral Palsy in 8-Year-Old Children in Three Areas of USA in 2002: A Multisite Collaboration. Pediatrics, 121, 547-554. https://doi.org/10.1542/peds.2007-1270

[23] González, R.C. and Sepúlveda, R.F.C. (2002) Tratamiento de la espasticidad en parálisis cerebral con toxina botulínica. Revista de Neurología, 34, 23-26.

[24] Young, R.R. (1994) Spasticity: A Review. Neuroly, 44, 12-20.

[25] Mongan, D., Dunne, K., O’Nuallain, S. and Gaffney, G. (2006) Prevalence of Cerebral Palsy in the West of Ireland 1990-1999. Developmental Medicine \& Child Neurology, 48, 892-895. https://doi.org/10.1017/S0012162206001952 